\title{
MANAGEMENT SYSTEMS IN THE CLASSROOM
}

Prospects for theFuture

Leonard Newton and Adrie Visscher

With Marko Bajec, Alison Kennedy, Coach Kereteletswe, Maureen Lambert, Pat Nolan, Arthur Tatnall and Chris Thorn

Key words: Management Information Systems, Knowledge Management Systems, classrooms, teachers

\section{INTRODUCTION}

Improving education is a prominent theme in many countries and, in the drive to raise standards, increasing quantities of data about pupils' attainment and progress is being generated. These data, collected at many levels in the educational system, provide a means to both monitor the performance of individual schools and to 'benchmark' and set targets at local and national levels.

Management Information Systems (MIS) enable the collation and interrogation of data at whole school, class and individual student levels. Such data, when collected from standardised national tests, permit comparisons to be made between similar schools against benchmark performance levels. However, this process may sometimes be contentious and raises questions about the validity of the chosen performance indicators and the instruments used to assess them. At another level of organisation, the impact of performance data on teachers' actions in the classroom remains problematic with fears that a teacher's focus may be too heavily directed to the measures of performance at the possible expense of teaching quality.

The original version of this chapter was revised: The copyright line was incorrect. This has been corrected. The Erratum to this chapter is available at DOI: 10.1007/978-0-387-35689-1_19 
This paper examines some issues related to the use of MIS in classroom contexts and considers some possible future needs of teachers that may present challenges to the designers of the next generation of MIS tools.

\section{CURRENT USES OF MIS - SOME PROBLEMS}

The Management Information Systems available in many schools and colleges offer a wide range of administrative functions, and generally perform these functions very well. Despite this, however, in most school systems not much use seems to be made of the information provided by MIS to directly affect what goes on in the classroom. In higher education, the evidence suggests that in many universities, partly because of the way that data are stored and accessed, absolutely no use can be made of data to improve teaching and learning. The data contained in typical MIS is intended to be used only for administrative purposes. The reason for this is related to the perceived stakeholders that the system was designed to serve. In most schools and universities, no consideration appears to have been given to the teaching function in MIS design. Thus, a tension exists between the different purposes of MIS in education: systems designed to provide school management information (for example, budget control, attendance figures, aggregated student performance data) are unlikely to adequately serve the information needs of teachers for classroom teaching purposes.

Schools, both individually and within systems, already possess robust management information systems, but evidence and anecdote indicate that teachers and managers under use them. This under-use raises questions about the competences required for decision-making using MIS and the capacity of users to implement them in their day-to-day activity. Requirement analyses of MIS for use in higher education suggest that it may not be possible to meet the diverse range of requirements for MIS in a single piece of software. In both school and higher education contexts, opportunities are missed to make use of information (much of it already stored in the MIS) to improve the quality of teaching and learning. Thus, a key issue to be addressed and resolved is how MIS users might more effectively exploit their potential in individual classrooms: particularly in ways that support both the broad standards agenda and, more importantly, the achievements of individual learners. 


\section{CHALLENGES FOR THE FUTURE}

In order to frame the subsequent discussion, we address the following groups of questions:

1. Given what is being done already, in which new and desirable ways can IT systems further be developed to support teaching and learning practices?

2. What are the benefits hoped for in new MISs? How and why might these be achieved?

3. How can we promote the use of these systems and how might the conditions of teachers be changed to facilitate the use of MIS? What are the design and implementation strategies required?

To address the first of these themes, we need to consider the weaknesses detected in the current state of MIS development, and in the use of MIS. Many of the weaknesses arise from the loose coupling of the design features of MIS to the needs of classroom teachers. Therefore, it is necessary to disassociate 'oversight systems' for accountability (which is about the management functions of an educational system, and instructional support systems) and system use that supports teaching and learning. Asking a single system to deliver both accountability and diagnosis (at least, at the individual level) provides mixed incentives for end users and significant design problems for designers. It is vital to remember that teaching and learning is a social process and that information that is relevant for making long-term decisions about staffing, changes in curriculum and standards, etc. is not appropriate for making day-to-day decisions.

Progress is required in at least two different areas. First, IT systems in education should be designed with the target populations in mind. This would be an improvement on the present situation where an unending series of add-on modules form a loose amalgam of disjoint sub-systems that fail to adequately meet the needs of any constituency of users. Second, 'knowledge repositories' for teachers are required as distinct from systems designed for managers. Such knowledge repositories might better support teachers as they search for resources to address the learning needs of their students, and their own personal and professional learning needs. A key task is, therefore, to identify the kinds of data and information that would be of use to classroom teachers.

With respect to the second question-set: namely, the benefits hoped for in new MIS, and how these might be realised; the needs of users should be more fully considered. To this end, the benefits of a MIS are best identified through examination of the requirements of different constituencies and linking these to system characteristics. Strategic decision-making can be better supported if the relevant outcome variables are tracked. For example, 
many school districts target particular areas of professional development. An appropriate evaluative framework for monitoring professional development might do the following: capture levels of staff participation; identify staff members' perception of the quality of the training; and measures of the impact of training. Taken together these elements would provide a coherent framework for judging the efficacy of a specific resource allocation strategy.

In the case of a learning support system, better alignment between pedagogy; learning standards; standards-based curriculum; and standardsaligned assessment could allow MIS designers to develop coherent support frameworks. For example, these frameworks might categorise curricular resources, professional development opportunities, and alternative assessment strategies. A framework could match student strengths and weaknesses with appropriate educational materials. Future MIS may therefore provide teachers with decision support systems that could enable them to make better judgements about the selection of particular curriculum resources for particular purposes. Such systems would require data entries to be clearly linked to specific curricular goals or standards. This capability would allow teachers to focus more time on teaching and less time on locating appropriate resources.

Student achievement in education is characterised by more than grade scores. Life-long learning records and portfolios provide a rich evidence base of the diverse achievements of learners and will contain more information than attainment records against benchmarked tests. Evidence of students' skills and achievements in other areas of their experience needs to be recorded and this evidence may or may not need to be digitised for storage in a MIS. However, the use of electronically stored portfolios raises questions of data protection and ownership of material; it may require a significant shift in perspective on issues of accountability and on the mutual understanding of the teacher-student dynamic. In any event, good portfolio development involves filtering and selection of information against clearly articulated standards and, in this respect, MIS could bring coherence to the portfolio process. Groupware systems could also be useful in this regard, as they offer an environment for group discussions. Using such systems students can open discussions on problems they would like to solve, and teachers can participate and help students to solve the problem. This is especially useful for students who have difficulties in being active in the classroom. Such developments are not currently addressed well in existing MIS and should feature more centrally in future developments.

The use of Knowledge Management Systems (KMS) as delivery systems for educational content may incorporate 'tracking' utilities that enable information on student progress through the KMS to be recorded in ways 
similar to those currently found in Integrated Learning Systems such as 'Successmaker'.

Portal technology holds the prospect of bringing MIS closer to end-users, as it endeavours to facilitate access and use. Development in portal technology is essentially user-centric: this means that designers are expected to spend much more time on acquiring specific requirements from different system users. Potentially, this might offer teachers and managers new opportunities to define what they really want.

Other possible classroom uses of MIS could include early diagnosis of problems likely to be encountered by a particular student by examination of achievement data for that student from previous years. Use of comparative data from a MIS, including demographic data, to provide examples for use in teaching and student assignments may be valuable too.

The third set of questions concern the design and implementation strategies required to facilitate wider use of MIS by teachers. A major issue arising from the earlier discussion is the need for MIS to offer a good match between the requirements of users. Thus, it might be asked: how can a MIS be built that is adaptable for use by the incumbents of different roles, i.e. that a system that is responsive to different kinds of 'role-use'. In this way the MIS of the future might more adequately reflect the needs and demands of teachers and managers.

In the case of management systems, their widespread use would require a shift from a focus on mere accountability to a more holistic view of assessment and its facilitation as part of a larger evaluation model. A more effective way to do this work is to find a district that has most of the basic technical and social elements in place and to co-opt its support in the process of system design, development and implementation. The design focus would need to be on the information needs of teachers - not just on the reporting needs of the larger educational system. Traditional approaches to MIS design show little likelihood of penetrating the realities of classroom practice and thus supporting and enhancing it. A design project that examined both the ways in which teachers create and use diagnostic information on the one hand, and then locate and integrate appropriate curricular resources would be an exciting and compelling departure from traditional approaches. It might, indeed, suggest directions for the future that are potentially more beneficial for a much wider constituency of educational professionals and be more responsive to their interests and concerns. 


\section{CONCLUDING REMARKS}

It is clear that educational users have different needs and purposes for MIS depending on their organisational context and role. The kinds of information required at different levels within education (individual / class / department / school etc) vary and may be available within a single MIS, but not all users need access to all information. In the future, some features of portal technology might have relevance in helping users find value in the information made available to them by MIS. Currently available MIS have limitations. Both users and designers need to appreciate that information made available to users through MIS requires interpretation to inform decisions and action. At the level of the classroom, MIS capabilities should be developed explicitly to address the needs of teachers. It is therefore legitimate to ask what the features might be of support systems for teachers mediated by MIS. A key question must be to ask what value a MIS adds to educational endeavours in classrooms. If we keep asking these questions, we may be successful in developing MIS that will help us to improve the quality of instruction as well as the performance of students and schools! 